\title{
Role of cytoreductive surgery and hyperthermic intraperitoneal chemotherapy in the treatment of gastric cancer
}

\section{Papel de la cirugía citorreductora y la quimioterapia intraperitoneal hipertérmica en el tratamiento del cáncer gástrico}

Horacio N. López-Basave1, Osvaldo A. Quiroz-Sandoval'*, Alejandro E. Padilla-Rosciano", Alberto M. León-Takahashi', Gerardo Miranda-Devora' y Araceli Arrollo-Monroy²

'Department of Gastrointestinal Tumors, National Cancer Institute of Mexico; 'Department of General Surgery, "Dr. Antonio González Guevara" Hospital. Mexico

\begin{abstract}
Patients with peritoneal carcinomatosis $(P C)$ of gastric origin have a poor prognosis of life with an average survival of 1-3 months. Systemic chemotherapy has improved the survival of those patients with gastric metastatic cancer at 7-10 months. However, this benefit could not be reproduced in those patients with PC. The current literature for the use of hyperthermic intraperitoneal chemotherapy (HIPEC) for gastric PC has significant variation related to patient selection, treatment intent (palliative vs. attempt at curative treatment), surgical technique, intraperitoneal chemotherapy agent utilized, and systemic chemotherapy administered adjuvantly. From the perspective of patient selection for cytoreduction and HIPEC, patients with extensive PC are not candidates. In addition, unresectable location would make a patient a poor candidate for cytoreduction and HIPEC. Optimally, those with positive peritoneal cytology alone could benefit most. However, the role of cytoreductive surgery and HIPEC in patients with PC of gastric origin has not yet been clarified.
\end{abstract}

KEY WORDS: Peritoneal carcinomatosis. Gastric cancer. Cytoreductive surgery. Hyperthermic Intraperitoneal chemotherapy.

\section{Resumen}

Los pacientes con carcinomatosis peritoneal (CP) de origen gástrico tienen un mal pronóstico de vida, con una supervivencia media de 1 a 3 meses. La quimioterapia sistémica ha mejorado la supervivencia de los pacientes con cáncer gástrico metastásico a los 7-10 meses. Sin embargo, este beneficio no se ha podido reproducir en los pacientes con CP. En cuanto a lo relacionado con la literatura actual para el uso de HIPEC (hyperthermic intraperitoneal chemotherapy) en la CP de origen gástrico, existe una variación significativa en la selección de pacientes, la intención de tratamiento (paliativo frente a intento de tratamiento curativo), la técnica quirúrgica, el agente quimioterapéutico intraperitoneal utilizado y la quimioterapia sistémica adyuvante administrada. Desde la perspectiva de la selección de pacientes para citorreducción y tratamiento con HIPEC, los pacientes con CP extensa no son candidatos. Además, lesiones irresecables por su localización harían al paciente un pobre candidato para citorreducción y tratamiento con HIPEC. De manera óptima, aquellos pacientes con citología peritoneal positiva en ausencia de CP son quienes más podrían beneficiarse. Sin embargo, el papel de la cirugía citorreductora y del tratamiento con HIPEC en los pacientes con CP de origen gástrico aún no ha sido esclarecido.

PALABRAS CLAVE: Carcinomatosis peritoneal. Cáncer gástrico. Cirugía citorreductora. HIPEC.

\footnotetext{
Correspondencia:

*Osvaldo A. Quiroz-Sandoval

Carril 19, ext. 2, int. 102, U. habitacional San Francisco II

Col. San Juan Xalpa, Del. Iztapalapa Date of reception: 21-03-2018

C.P. 09850, Ciudad de México, México Date of acceptance: 24-04-2018

E-mail: osvaldo_quiroz80@ hotmail.com DOI: 10.24875/CIRU.M18000040
}

Cir Cir. 2018;86:277-284

Contents available at PubMed www.cirugiaycirujanos.com 


\section{Introduction}

Patients with peritoneal carcinomatosis (PC) of gastric origin have a poor prognosis of life with an average survival of 1-3 months. Systemic chemotherapy has improved the survival of those patients with gastric metastatic cancer at 7-10 months. However, this benefit could not be reproduced in those patients with PC.

Since the 90s, cytoreductive surgery combined with the use of intraperitoneal chemotherapy (IPC) under the conditions of hyperthermia (HIPEC) has allowed to offer an alternative treatment in patients with $P C$ of gastrointestinal origin. Glehen et al. demonstrated a mean survival of 32 months in those patients with PC of colorectal origin when complete cytoreduction and HIPEC are given compared to the 7 months of median survival reported in patients treated with systemic palliative treatment ${ }^{1}$. Similarly, Elias et al. demonstrated a 5 -year survival of $51 \%$ compared to $13 \%$ reported in patients treated with systemic palliative chemotherapy. However, the role of cytoreductive surgery and HIPEC in patients with PC of gastric origin has not yet been clarified².

\section{Mechanisms of peritoneal dissemination}

A priori, the direct extension of the disease within the peritoneal cavity, either spontaneously or during surgical maneuvers performed by surgeons, are the most frequent mechanism of peritoneal dissemination. Desquamation of tumor cells after tumor rupture and its implantation does not follow an anarchic spread, being predictable the distribution of peritoneal disease. Carmignani and Sugarbaker found that the spread of tumor cells followed a pattern determined by the circulation of the peritoneal fluid, which tended to project the tumor cells into the subphrenic spaces, being also affected the areas of reabsorption of the same, regardless of the etiology of the tumor ${ }^{3}$. They also observed that regions such as the serosa of the small intestine were regions that, due to their mobility, saw the possibility of implantation due to purely physical problems, by preventing the seating of the tumor cells by peristalsis. Other less mobile regions, such as the ileocecal region, the gastric antrum, or the peritoneal surface of the small intestine, do not have this protective mechanism and are often affected by tumor deposits.

This mechanism explains the genesis of most PC cases but does not explain all situations. We know that patients with perforated colon adenocarcinoma do not have significantly higher incidence rates of PC with respect to certain low rectal tumors without communication with the peritoneal cavity, in which case they may present peritoneal disease at the time of diagnosis, and that certain extraabdominal tumors may manifested in the form of PC. Thus, lymphatic dissemination route has been proposed as an alternative in these cases.

The histological characterization of the peritoneal lymphatic system includes the presence of lymphatic stomas that connect the peritoneal surface with the subperitoneal lymphatic system, as well as the aggregation of lymphatic vessels of neoformation, macrophages, and lymphocytes (milky spots), present in the greater omentum in addition to the peritoneum. According to several independent observations, tumor cells can pass through these lymphatic stomas and become trapped into the milky spots. Growth factors and angiogenic factors would allow implantation of tumor cells on the peritoneal surface. Thus, the extention and disemination of the disease would be favored by the presence of a larger number of lymphatic vessels and stomas as occurs in the greater omentum, diaphragmatic regions, and pelvis.

One of the theories postulated to explain peritoneal dissemination in those cases in which the primary tumor is not affecting serosa refers to contamination of the peritoneal cavity after lymphatic dissection through lymphatic channels opened by the same surgical manipulation, in which case, they could release viable tumor cells. Some authors have found the presence of free intraperitoneal cancer cells (IPFCC) after analyzing the peritoneal lavage fluid in the abdominal cavity after lymphatic dissection in patients whose disease is limited only to the submucosal and muscular layer itself (14.3\% and $26.7 \%$, respectively) ${ }^{4}$.

After analyzing a series of 1272 cases of gastric carcinoma taken to surgery for curative purposes and lymphatic dissection of the second ganglionic barrier (D2) as initial treatment by Kumamoto University, Shimada et al. reported recurrence at the peritoneal level in $0.4 \%$ of cases with submucosal invasion (1 of 127 cases) and $4.4 \%$ of those with invasion of the muscularis propria (6 of 136 cases); of which, $86 \%$ had lymph node metastases and/or proven lymphatic invasion ${ }^{5}$. It is possible to mention that the rest of the patients mentioned above who did not develop peritoneal recurrence had no lymph node metastases and/or lymphatic invasion. 


\section{Usefulness of peritoneal lavage in patients with gastric cancer}

Some studies have shown that up to $30 \%$ of patients with T1-weighted disease evaluated by endoscopic ultrasonography and with absence of metastatic disease evident in the tomographic study may present evident metastatic disease at peritoneal cavity, after laparoscopic evaluation ${ }^{6}$. Positron-emission tomography-computed tomography (PET-CT) is usually superior to $\mathrm{CT}$ for the detection of distant metastases, but it suffers in its sensitivity while in PC detection.

PET-CT cannot replace laparoscopy which clearly offers the advantages of direct visualization of the peritoneal cavity.

Patients with radiologically resectable disease, in whom IPFCC has been detected, have documented early recurrences and poor survival rates despite achieving $\mathrm{R} 0$ after resection with curative intention. Therefore, the presence of IPFCC is a marker of the early development of peritoneal micrometastases in patients with absence of visible peritoneal disease during laparoscopy. In this context, peritoneal wash cytology (PWC) during staging laparoscopy provides invaluable information, predicting the possibility of peritoneal recurrence or failure, and allowing a better selection of the therapeutic approach aimed at these cases. The Japanese Classification of Gastric Carcinoma (JCGC) recommends performing PWC as part of the routine evaluation and staging since 1990 and placing those patients with IPFCC within the clinical stage IV ${ }^{7}$. While the Society of American Gastroenterologists and Endoscopic Surgeons places the PWC as part of the evaluation process during staging laparoscopy ${ }^{8}$, the European Society for Medical Oncology defines the PWC evaluation process as a non-mandatory practice ${ }^{9}$. Recently, the American Joint Committee on Cancer included the evaluation of the PWC as part of the $7^{\text {th }}$ TNM staging process edition. However, its implementation continues to be an unstable practice in western countries ${ }^{10}$. One proposal to increase the sensitivity of the PWC is to perform washes in multiple cavities. Most surgeons who treat gastric cancer in the world only perform peritoneal lavage on the Douglas sac as recommended by the JCGC. Interestingly, Homma et al. showed an increase in sensitivity when the lavages were performed in the left subphrenic recess, right subphrenic recess, omental bursa, and Douglas sac ${ }^{11}$. However, most of the strategies to increase the sensitivity of the PWC fall into the histopathological evaluation, implementing immunoassay techniques as well as molecular biology. The immunoassay technique using carcinoembryonic antigen-associated antigens (CEA) has shown a benefit in the detection of $14 \%$ intraperitoneal free tumor cells on the conventional cytology evaluation technique ${ }^{12}$.

Today, numerous studies have demonstrated superior sensitivity using reverse transcriptase polymerase chain reaction (RT-PCR) technique for the detection of IPFCC. However, this technique is expensive and takes more time to be performed, which makes it difficult to apply as a method of intraoperative evaluation, coupled with a percentage of questionable specificity. Despite this, it has been implemented as the standard method of clinical evaluation during peritoneal lavage in Japan since 2006. Kuramoto et al. demonstrated a 5 -year overall survival of $43.8 \%$ in a randomized controlled trial in those patients with positive peritoneal cytology in the absence of visible ( $\mathrm{CY}+/ \mathrm{P}-)$ peritoneal implants treated with surgery and extensive peritoneal lavage (EIPL) followed by normothermic IPC ${ }^{13}$.

\section{Role of RT-PCR PWC in gastric cancer}

The invention of the PCR by Mullis et al. in 1985 has revolutionized molecular biology applied in medicine. PCR is an in vitro technique used to enzymatically amplify a specific region of DNA whose sequence is known. Whereas previously only minimal amounts of a specific gene could be obtained, even a single copy of a gene can now be amplified with RT-PCR in up to one million copies in a few hours.

The conventional RT-PCR methodology used for the detection of tumor nucleotide bands in agarose gel has a high sensitivity. However, it does not always have adequate specificity due to the high percentage of false positives obtained from the weak expression of CEA by non-cancerous cells such as leukocytes, macrophages, mesothelial, and hematopoietic cells present in the abdominal cavity at the time of laparotomy. The detection of high concentrations of DNA from necrotic cells in the peritoneal cavity can be misinterpreted as tumor progression, increasing the number of false positives expressed. As mRNA is unstable in non-viable cells, detection of mRNA from viable cells is usually a more reliable method of detection by RT-PCR technique.

In addition to the CEA, several genetic markers of peritoneal lavage have now been identified that are specific for tumor cells, which have the ability to predict the risk of peritoneal recurrence even in CY-/P- patients, with a risk of $50 \%$ in $\mathrm{CY}+\mathrm{P}$ - patients for $\mathrm{CK} 20$ (cytokeratin 20) by RT-PCR, as well as $67 \%$ and $71 \%$ 
for FABP1 and MUC2, respectively. Likewise, this risk is usually $<5 \%$ when these three markers are negative $e^{14,15}$.

The quantitative technique for real-time RT-PCR is a specific nucleotide detection method, with the ability to detect up to 10 IPFCC in the peritoneal lavage fluid per $1 \times 10^{7}$ leukocytes, indicating comparable sensitivity with conventional RT-PCR technique. It is able to perform a complete analysis in a period of time that varies between 70 and $90 \mathrm{~min}$, which makes it ideal for its application during the transoperative evaluation. It has a sensitivity and specificity of $64.9 \%$ and $82.7 \%$ for the detection of CEA mRNA and $54.6 \%$ and $80.3 \%$ for detection of CK20 mRNA, respectively. Katsuragi et al. demonstrated in a prospective trial with 124 patients that the combination of both mRNA levels for CEA and CK20 increases sensitivity to $81.5 \%$ without decreasing its specificity ${ }^{16}$. Kodera et al. published the 5-year survival of 284 patients treated with gastrectomy for curative purposes and D2 lymphadenectomy as initial treatment with a mean follow-up of 2495 days, in whom PWC performed before and after the surgical procedure using RT-PCR technique. It was reported a sensitivity and specificity of $88.5 \%$ and $81.6 \%$ respectively for peritoneal lavage analysis performed after lymphatic dissection, with a positive and negative predictive value of $64.5 \%$ and $94.9 \%$ compared to conventional cytology $(47.4 \%, 97.1 \%, 86.1 \%$ and $83.0 \%$, respectively). The presence of lymphatic metastases and the positivity of peritoneal lavage following lymphatic dissection using the RT-PCR technique were the only independent factors of mortality associated with the subsequent onset of PC. However, it was also reported positivity to peritoneal lavage analysis in $9.5 \%$ of patients with $\mathrm{T} 1$ disease in whom peritoneal recurrence was never documented, suggesting the possibility that the percentage of false positives could exceed $10 \%$ of the samples as a factor against the specificity to this technique. The quantification of glyceraldehyde 3-phosphate dehydrogenase (GAPDH) and the ratio between CEA and GAPDH ARNA mRNA ratio have been used as a feasibility parameter ${ }^{17}$. However, it might not adequately reflect the probability of developing PC, because it is the number of cancer cells and not the proportion of cancer cells relative to intraperitoneal cells.

\section{Role of exhaustive peritoneal lavage as prophylaxis for peritoneal recurrence}

Results in terms of 5-year overall survival in the literature according to the series of patients treated by gastrectomy for curative purposes accompanied by D2 lymphatic dissection show that in western countries around $40 \%$ is found, whereas in the east, this survival exceeds $60 \%$. This is possibly due to three main causes: first, surgical groups in the east exclude those patients with $\mathrm{CY}+/ \mathrm{P}$-because they are associated with a worse prognosis, second, there is a larger population of patients with gastric cancer incipient due to the final analysis of the surgical part of those patients enrolled in the databases of eastern countries, and finally, there seems to be a genetic difference between eastern and western populations. However, the major problem at present is the high percentage of peritoneal recurrence after surgery with curative intention, which is usually within the first 2 years of follow-up and usually exceeds $50 \%$ of cases.

Based on the literature, those patients who underwent D2 lymphatic dissection as part of the surgical treatment will be more likely to develop recurrence at the peritoneal level, as occurs in several oriental series, in comparison to those patients who did not undergo D2 lymphatic dissection, with a higher rate of recurrence at the local level, as in western countries. The existence of IPFCC in CY +/P-patients supposes a moment in which the conditions for peritoneal dissemination have not yet occurred; Presupposing a possibility of treatment before the development of the PC. Marutsuka et al. treated 63 gastric cancer patients with surgery as first-line therapy (44.6\% T3-T4), performing PWC at the time of staging laparotomy and subsequently to D2 lymphatic dissection. He also performed EIPL with $1 \mathrm{~L}$ of saline solution at $0.9 \%$ after the extraction of the tumor, completely aspirating the residual liquid in all areas of decline and doing the same procedure for 10 times in a row and covering the sites of cut of the enteric tract with a gauze for later reconstruction. By means of the analysis of the peritoneal lavage fluid by means of RT-PCR technique in its different times, it was possible to conclude to the multivariate analysis that the presence of lymphatic metastases was the only independent factor related to the existence of IPFCC after the lymphatic dissection. Moreover, the quantitative analysis showed that the number of IPFCC decreased with each cycle of EIPL performed, achieving a dilution of $3.8 \times 10^{5} \pm$ $1.4 \times 10^{5}$ to $2.8 \pm 1.5$ cells per $100 \mathrm{ml}$ after 6 or 8 cycles of EIPL. Eventually, copies of CEA mRNA disappeared completely after the 7-9 cycles of EIPL performed ${ }^{18}$. It should be mentioned that in some cases where nodular metastases and/or lymphatic invasion were found, it was not possible to detect CEA or 
CK20 mRNA after analysis of the peritoneal lavage fluid after D2 lymphatic dissection. Thus, it makes us assume that the lymphatic vessels could have been blocked after the use of ligature or electrocautery during the surgical manipulation. These patients did not develop PC after a 2-year follow-up.

In another randomized prospective study, Kuramoto et al. randomized 88 patients with $C Y+/ P$, who were treated with surgery with curative intention as first line of treatment into three groups, the first group treated exclusively with surgery, the second group was associated with IPC with cisplatin (CDDP), and the third group associated with IPC with CDDP plus EIPL. They observed a 5 -year survival of $43.8 \%$ for the EIPL-associated group, with a decrease in peritoneal recurrence of $80-90 \%$ to $40 \%$. Furthermore, they documented a difference of almost $40 \%$ in relation to the other two groups ${ }^{4}$.

These results suggest that surgical manipulation after lymphatic dissection may be the most important factor during the dissemination of free tumor cells into the peritoneal cavity and consequently the probability of peritoneal recurrence in patients with gastric cancer candidates for resection.

\section{Role of normothermic IPC as adjuvant after surgical resection in addition to EIPL}

A multicenter study of 88 patients with locally advanced $\mathrm{CY}+/ \mathrm{P}$ - gastric cancer was randomized into 3 groups (surgery with curative intention, surgery with curative intention + IPC and surgery with curative intention + CDP-based EIPL-IPC). Kuramoto et al. reported a 5 -year survival of $43.8 \%$ in patients treated with IPC as an adjuvant in addition to surgery with curative intention + EIPL, compared to the group treated only with surgery + IPC $(4.6 \%, p<0.0001)$ and the treated group only by surgery alone $(0 \%, p<0.0001)$ and reported morbidity and mortality rates of $1.5 \%$ and $0.5 \%$, respectively, for the group treated with EIPL + IPC ${ }^{13}$.

Likewise, the EIPL + IPC surgery group reported a significantly lower incidence for peritoneal recurrence compared to the other groups, finding the multivariate analysis the use of EIPL as the most important impact factor. These results are comparable with previous publications of similar characteristics where the authors report an average median survival of 35 months and a 5 -year survival of $42.1 \%$ for those patients treated with EIPL + IPC in addition to surgery with curative intention as adjuvant, in $91 \mathrm{CY}+/ \mathrm{P}$ - patients randomized in similar groups ${ }^{19}$.
To date, there are only three prospective randomized studies comparing the use of IPC as an adjunct to surgical treatment versus surgery alone. Kutamoto el al. reported a 5- and 3-year survival of $4.6 \%$ and $18 \%$, respectively, using $100 \mathrm{mg}$ of CDDP for $1 \mathrm{~h}$ inside the peritoneal cavity after surgical treatment in 29 patients with $\mathrm{CY}+/ \mathrm{P}$ - gastric cancer and documented peritoneal recurrence in $79.3 \%$ of patients after a 5-year follow-up ${ }^{20}$. Similarly, Shimada et al. reported a 2-year survival of $14.3 \%$ in $7 \mathrm{CY}+/ \mathrm{P}$ - patients using the same regimen mentioned above, reporting a peritoneal recurrence of $85.7 \%$ following a 2-year follow-up ${ }^{13}$. On the other hand, Imano et al. documented a 3-year survival of $56 \%$ in 10 patients with locally advanced gastric cancer (20\% T3 and $80 \%$ T4) CY $+/ \mathrm{P}$ - treated with paclitaxel-based IPC $80 \mathrm{mg} / \mathrm{m}^{2}$ for $24 \mathrm{~h}$ inside the peritoneal cavity, in addition to adjuvant treatment with $\mathrm{S} 1$ without documenting peritoneal recurrence. It should be mentioned that he reported a morbidity of $30 \%$ associated with hematological toxicity grade $3-4^{21}$. These differences in results can be explained due to the heterogeneity of the populations, where the study by Kuramoto et al. only enrolled $6.9 \%$ of patients with serous invasion compared to the study by Imano et al. where $40 \%$ of patients with N3a lymphatic invasion and $30 \%$ N3b were documented. However, despite these differences, it seems that the addition of IPC to surgical treatment for curative purposes favors overall survival despite the fact that the sum of the risk ratio does not reach statistical significance (Hazard ratio [HR] 0.70, 95\% confidence interval $[\mathrm{Cl}] 0.47-1.04 ; p=0.08$ ). This finding could be related to the wide confidence interval during the estimation of the risk ratio in the study by Shimada et al. (HR 1.19, 95\% Cl 0.40-3.55). Despite this, a significant variance was not demonstrated between the studies $\left(\mathrm{T} 2=0 ; I^{2}=0 \%\right)^{22}$.

\section{Role of cytoreductive surgery and HIPEC in the treatment of gastric cancer}

The main cause of treatment failure in patients with gastric cancer treated with surgery with curative intention is peritoneal recurrence. Therefore, it is reasonable to offer a preventive treatment, which may reduce the possibility of peritoneal recurrence in those patients at high risk.

Currently, the combination of surgical cytoreduction and HIPEC remains the only existing therapeutic strategy that allows to improve the long-term survival of patients with PC. Glehen et al. reported a 5-year 
Table 1. Short-term results in cytoreduction and HIPEC in gastric adenocarcinoma

\begin{tabular}{|c|c|c|c|c|c|c|c|c|c|c|c|c|c|}
\hline Author & Num. & Mortality & $\begin{array}{l}\text { Related } \\
\text { mortality }\end{array}$ & $\begin{array}{l}\text { Related } \\
\text { morbidity }\end{array}$ & Reint & Sepsis & $\begin{array}{c}\text { Anastomotic } \\
\text { leak }\end{array}$ & Fistulae & Abscess & Ileus & $\begin{array}{l}\text { Hem } \\
\text { toxicity }\end{array}$ & $\begin{array}{l}\text { ICU Hosp } \\
\text { Days }\end{array}$ & Hosp \\
\hline Glehen & 159 & $6.5 \%$ & 11 & & & & & & & & & & \\
\hline Yang & 21 & $10.7 \%$ & 3 & $14.3 \%$ & & 1 & 1 & & 1 & 2 & & & $1-3$ \\
\hline Shen & 43 & $4 \%$ & & $43 \%$ & & & & & & & & 15 & 2 \\
\hline Scaringi & 26 & $11 \%$ & 1 & $27 \%$ & & & & 9 & 5 & & 2 & 16 & \\
\hline Roviello & 12 & $1.6 \%$ & 1 & $27.9 \%$ & $8.2 \%$ & & & 5 & 2 & 1 & 5 & 7 & \\
\hline Farma & 9 & $5.6 \%$ & 1 & $55.6 \%$ & & & & & 1 & & 3 & & \\
\hline Yonemura & 107 & $7 \%$ & 3 & $21.5 \%$ & & & 6 & 1 & 6 & & & & \\
\hline Mussa & 7 & $14.3 \%$ & 1 & & & 1 & & & & & & & \\
\hline Fujimura & 15 & $0 \%$ & 0 & $50 \%$ & $33.3 \%$ & & & & 2 & & & & \\
\hline Beaujard & 42 & $3.6 \%$ & 3 & $9.6 \%$ & $4.8 \%$ & & 1 & & & 2 & 3 & 11 & \\
\hline Total & 441 & $4.8(0-14.3)$ & 19 & 21.5 & & & & & & & & & \\
\hline
\end{tabular}

Reint: reintervention, Hem: hematologic, Hosp: hospitalization, HIPEC: hyperthermic intraperitoneal chemotherapy

survival rate of $23 \%$ in a retrospective study of 159 patients with gastric carcinomatosis treated with complete cytoreduction and HIPEC ${ }^{23}$. Yang et al. demonstrated the benefit of HIPEC in patients undergoing complete cytoreduction using a prospective randomized phase III study using CDDP and Mitomycin C, with an average survival of 11 months compared with 6.5 months of the control group treated by complete cytoreduction only $(p=0.046)$. It has now been reported that the benefit of HIPEC is greater in patients with synchronous carcinomatosis ${ }^{24}$.

Fujimoto et al. reported a significant reduction in peritoneal recurrence $(p<0.001)$ and an increase in overall survival $(p=0.03)$ in 141 patients treated with HIPEC as adjuvant to curative surgery in patients with locally advanced gastric adenocarcinoma without evidence of PC, without reporting postoperative adverse effects $^{25}$. Yonemura et al. randomized 139 patients in 3 arms, reporting a 5 -year survival of $42 \%$ for the surgery group, $43 \%$ for the group treated with surgery and IPC, and $61 \%$ for those treated with surgery and HIPEC $^{26}$. In the same way, Kim and Bae published the results of a controlled study with 103 patients with serous affection by gastric adenocarcinoma, taken to surgical resection and HIPEC and documented a significantly higher percentage of survival at 5 years compared to the control group treated with resection alone $(p=0.0379)$. The most common was locoregional recurrence in the experimental arm, treated with surgery and HIPEC, compared to the peritoneal recurrence of the control group treated only by resection $^{27}$. In the meta-analysis published by Yan et al., the adjuvant treatment with HIPEC was shown to significantly increase the percentages of overall survival in gastric cancer patients with complete cytoreduction $(\mathrm{HR}=0.60[95 \% \mathrm{Cl}=0.43-0.83 ; p=0.002])^{28}$. Gill et al. documented 1 - and 5 -year survival of $43 \%$ and $13 \%$, respectively, with an average survival of 15 months for those patients undergoing $\mathrm{CCO} / \mathrm{CC} 1$ and $\mathrm{HI}$ PEC in a review of 441 patients with PC of gastric origin $^{29}$ (Tables 1 and 2).

\section{Role of early post-operative intraperitoneal chemotherapy (EPIC) in the treatment of gastric cancer}

Under the hypothesis that some IPFCCs could be implanted in the wounds after surgical resection being isolated by fibrin nests during the healing phase. Yu et al. administered a chemotherapy regimen based on MMC and 5-FU using an intraperitoneal catheter in 64 patients with metastatic gastric carcinoma randomized to two equal arms, offering gastrectomy alone versus gastrectomy + EPIC and recorded an average survival of 4.9 and 27.8 months for the groups treated only with surgery compared to the + EPIC surgery group $(p<0.01)^{30}$. Jeung et al. compared 248 patients with locally advanced gastric cancer with surgery alone versus palliative surgery + EPIC $(23 \%$ III and $5 \%$ IV vs. $57 \%$ III and $28 \%$ IV, respectively) using an MMC and 
H. N. López-Basave, et al.: Role of Cytoreductive Surgery and HIPEC
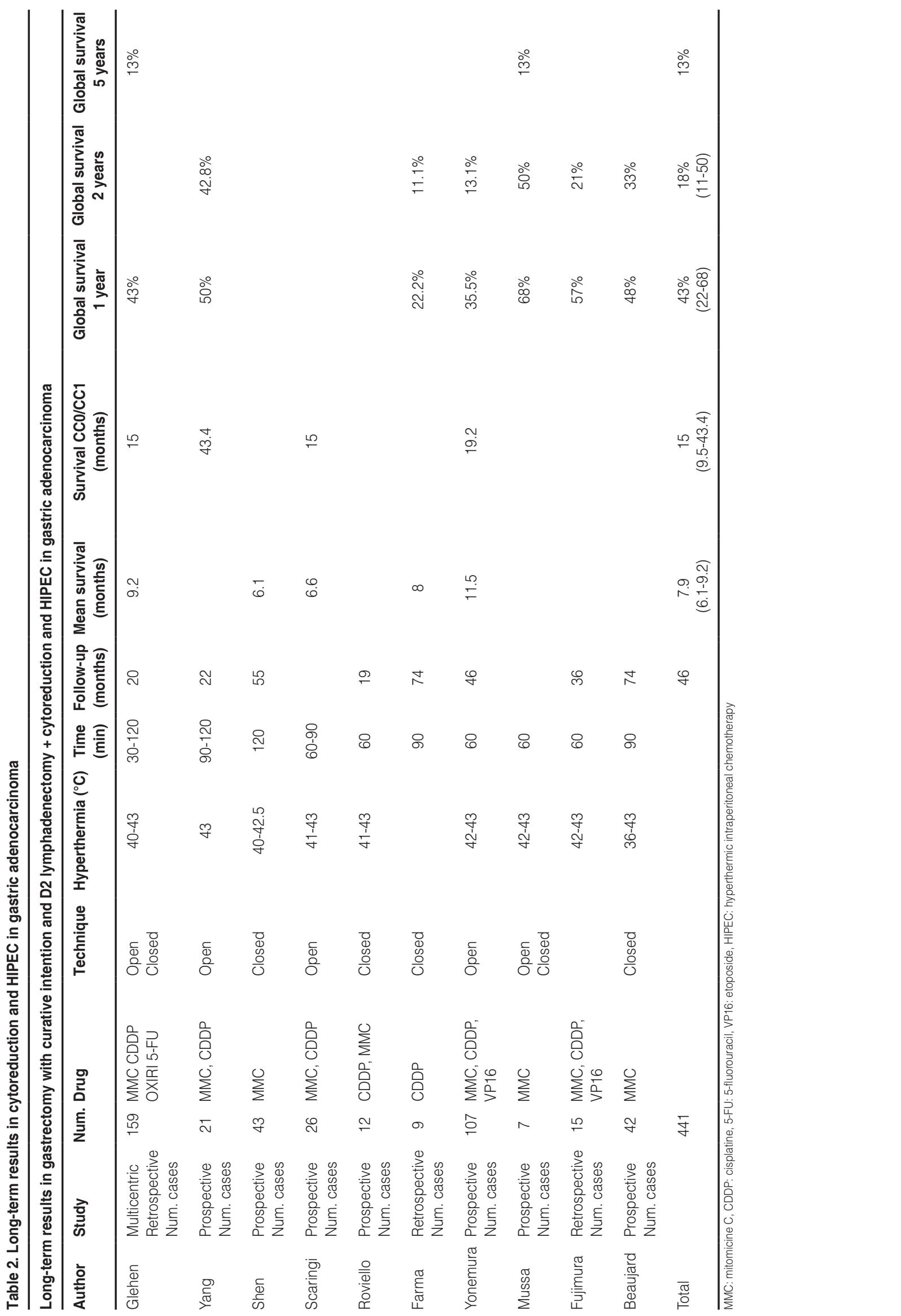
5-FU regimen. Registered a statistically significant increase in survival for patients with serosal invasion of $25 \%$ and $52 \%$ for both arms respectively $(p=0.0004)$ and $22 \%$ and $46 \%$ respectively for the subgroup of patients with lymph node metastases $(p=0.0027)^{31}$.

\section{Conclusions}

The current literature for the use of HIPEC for gastric $\mathrm{PC}$ has significant variation related to patient selection, treatment intent (palliative vs. attempt at curative treatment), surgical technique, IPC agent utilized, and systemic chemotherapy administered adjuvantly.

Currently, some cancer centers rely on multimodal treatment strategies based on the different characteristics of the different types of chemoprophylaxis treatment, such as the Shizuoka Cancer Center where they appear to have better results when implementing a regimen based on pre-operative IPC followed by curative surgery, D2 lymphadenectomy, and cytoreduction followed by HIPEC and EPIC for patients with gastric cancer and a PC index no $>12$ points.

From the perspective of patient selection for cytoreduction and HIPEC, patients with extensive PC are not candidates. In addition, unresectable location would make a patient a poor candidate for cytoreduction and HIPEC. Optimally, those with positive peritoneal cytology alone could benefit most. However, the role of cytoreductive surgery and HIPEC in patients with PC of gastric origin has not yet been clarified.

\section{References}

1. Glehen $\mathrm{O}$, Kwiatkowski $\mathrm{F}$, Sugarbaker $\mathrm{PH}$, et al. Cytoreductive surgery combined with perioperative intraperitoneal chemotherapy for the management of peritoneal carcinomatosis from colorectal cancer: a multi-institutional study. J Clin Oncol. 2004;22:3284-92.

2. Elias $\mathrm{D}$, Lefevre $\mathrm{JH}$, Chevalier J, et al. Complete cytoreductive surgery plus intraperitoneal chemohypertermia with Oxaliplatin for peritoneal carcinomatosis of colorectal origin. J Clin Oncol. 2004;27:681-5.

3. Carmignani CP, Sugarbaker TA, Bromley CM, Sugarbaker PH. Intraperitoneal cancer dissemination: mechanisms of the patterns of spread. Cancer Metastasis Rev. 2003:22:465-72.

4. Marutsuka T, Shimada S, Shiomori K, et al. Mechanisms of peritoneal metastasis after operation for non-serosa-invasive carcinoma: an ultrarapid detection system for intraperitoneal free cancer cells and a prophylactic strategy for peritoneal metastasis. Clin Can Res. 2003:9:678-85.

5. Shimada S, Yagi Y, Shiomori K, et al. Characterization of early gastric cancer and proposal of optimal therapeutic strategy. Surgery. 2001;129: 714-9.

6. Sarela Al, Lefkowitz R, Brennan MF, Karpeh MS. Selection of patients with gastric adenocarcinoma for laparoscopic staging. Am J Surg. 2006;191:134-8.

7. Japanese Gastric Cancer Association. Japanese Classification of Gastric Carcinoma - $2^{\text {nd }}$ English edition. Gastric Cancer. 1998;1:10-24.

8. Hori Y. Diagnostic laparoscopy guidelines. SAGES guidelines committee. Surg Endosc. 2007;22:1353-83.
9. Okines A, Verheij M, Allum W, et al. Gastric cancer: ESMO clinical practice guidelines for diagnosis, treatment and follow-up. Ann Oncol. 2010;21:v50-4.

10. Sobin L, Gospodarowicz M, Wittekind C. TNM Classification of Malignant Tumours. $7^{\text {th }}$ ed. New York: Wiley 2010.

11. Homma Y, Ushida S, Yamada M, Kobayashi H, Suzuki K. Positive peritoneal washing cytology in multiple cavities can predict poor prognosis of advanced gastric cancer patients. Ann Surg Oncol. 2010;17:455-60.

12. Benevolo M, Mottolese M, Cosimelli M, et al. Diagnostic and prognostic value of peritoneal immunocytology in gastric cancer. $\mathrm{J}$ Clin Oncol. 1998;16:3406-11.

13. Kuramoto $M$, Shimada $S$, Ikeshima $S$, et al. Extensive intraoperative peritoneal lavage as a standard prophylactic strategy for peritoneal recurrence in patients with gastric carcinoma. Ann Surg. 2009;250:242-6.

14. Ceroni $M$, Viñuela $F$, Norero $M$, et al. Prevención de la recurrencia peritoneal en el tratamiento quirúrgico del cáncer gástrico. Rev Chil Cir. 2014;66:283-91.

15. Satoh $\mathrm{Y}$, Mori K, Kitano K, et al. Analysis for the combination expression of $\mathrm{CK} 20, \mathrm{FABP} 1$ and MUC2 is sensitive for the prediction of peritoneal recurrence in gastric cancer. Jpn J Clin Oncol. 2012;42:148-52.

16. Katsuragi K, Yashiro M, Sawada T, et al. Prognostic impact of PCR-based identification of isolated tumour cells in the peritoneal lavage fluid of gastric cancer patients who underwent a curative $\mathrm{R} 0$ resection. $\mathrm{Br} J$ Cancer. 2007;97:550-6.

17. Kodera $\mathrm{Y}$, Nakanishi $\mathrm{H}$, Ito $\mathrm{S}$, et al. Prognostic significance of intraperitoneal cancer cells in gastric carcinoma: analysis of real time reverse transcriptase-polymerase chain reaction after 5 years of followup. J Am Coll Surg. 2006;202:231-6.

18. Kodera $\mathrm{Y}$, Nakanishi $\mathrm{H}$, Ito $\mathrm{S}$, et al. Quantitative detection of disseminated free cancer cells in peritoneal washes with real-time reverse transcriptase-polymerase chain reaction: a sensitive predictor of outcome for patients with gastric carcinoma. Ann Surg. 2002;235:499-506.

19. Kuramoto M, Shimada S, Ikeshima S, et al. A proposal of a practical and optimal prophylactic strategy for peritoneal recurrence. J Oncol. 2012;2012:340380.

20. Rosemberg $R$, Nekarda $H$, Bauer $P$, et al. Free peritoneal tumour cells are an independent prognostic factor in curatively resected stage IB gastric carcinoma. Br J Surg. 2006;93:325-31.

21. Shimada S, Tanaka E, Marutsuka T, et al. Short communication: extensive intraoperative peritoneal lavage and chemotherapy for gastric cancer patients with peritoneal free cancer cells. Gastric Cancer. 2002;5:168-72.

22. Imano $\mathrm{M}$, Imamoto $\mathrm{H}$, Itoh $\mathrm{T}$, et al. Impact of intraperitoneal chemotherapy after gastrectomy with positive cytological findings in peritoneal washings. Eur Surg Res. 2011;47:254-9.

23. Glehen O, Gilly FN, Arvieux C, et al. Peritoneal carcinomatosis from gastric cancer: a multi-institutional study of 159 patients treated by cytoreductive surgery combined with perioperative intraperitoneal chemotherapy. Ann Surg Oncol. 2010;17:2370-7.

24. Yang XJ, Huang CQ, Suo T, et al. Cytoreductive surgery and hyperthermic intraperitoneal chemotherapy improves survival of patients with peritoneal carcinomatosis from gastric cancer: final results of a phase III randomized clinical trial. Ann Surg Oncol. 2011;18:1575-81.

25. Fujimoto S, Takahashi M, Mutou T, Kobayashi K, Toyosawa T. Successful intraperitoneal hyperthermic chemoperfusion for the prevention of postoperative peritoneal recurrence in patients with advanced gastric carcinoma. Cancer. 1999;85:529-34.

26. Yonemura $Y$, de Aretxabala X, Fujimura T, et al. Intraoperative chemohyperthermic peritoneal perfusion as an adjuvant to gastric cancer: final results of a randomized controlled study. Hepatogastroenterology. 2001; 48:1776-82.

27. Kim JY, Bae HS. A controlled clinical study of serosa-invasive gastric carcinoma patients who underwent surgery plus intraperitoneal hyperthermo-chemo-perfusion (IHCP). Gastric Cancer. 2001;4:27-33.

28. Yan TD, Black D, Sugarbaker PH, et al. A systematic review and meta-analysis of the randomized controlled trials on adjuvant intraperitoneal chemotherapy for resectable gastric cancer. Ann Surg Oncol. 2007; $14: 2702-13$.

29. Gill RS, Al-Adra DP, Nagendran J, et al. Treatment of gastric cancer with peritoneal carcinomatosis by cytoreductive surgery and HIPEC: a systematic review of survival, mortality, and morbidity. J Surg Oncol. 2011;104:692-8.

30. Yu W, Whang I, Chung HY, Averbach A, Sugarbaker PH. Indications for early postoperative intraperitoneal chemotherapy of advanced gastric cancer: results of a prospective randomized trial. World J Surg. 2001;25:985-90.

31. Jeung HC, Rha SY, Jang WI, Noh SH, Chung HC. Treatment of advanced gastric cancer by palliative gastrectomy, cytoreductive therapy and postoperative intraperitoneal chemotherapy. Br J Surg. 2002;89:460-6. 